\title{
The Effects of the Correlation of Electric Materials on Forecasting and Stock Control
}

\author{
Aiping Jiang, PhD \\ Junjun Gao, PhD \\ Qiuguo Chi, MA \\ Sixian Zheng \\ Shanghai University, China
}

doi: 10.19044/esj.2016.v12n22p107 URL:http://dx.doi.org/10.19044/esj.2016.v12n22p107

\begin{abstract}
Forecasting and stock control play an important role in the electric companies because outstanding forecasting and stock control increase service level obviously and decrease stock cost effectively. However, the majority of the electric materials are intermittent demand, resulting in poor forecasting and stock control performance. Therefore, exploring the reasons that affect forecasting performance and stock control is necessary. This paper explores the effects of the correlation of intermittent electric materials on forecasting and stock control. First, we divide the correlation into three categories: autocorrelation in demand sizes, autocorrelation in intervals and cross-correlation between demand size and interval. Forecasting by SBA approach and using periodic dynamic inventory strategy $(T, S)$ to control stock, exploring the effects of these three correlations on forecast accuracy, stock cost and service level. The data shows that correlations of electric materials affect their forecasting and stock control, which will help company find more accurate forecast approach and lower the cost of stock in the future.
\end{abstract}

Keywords: Correlation; Forecasting Accuracy; Average Cost; Average Service Level

\section{Introduction}

One of the most critical issues for electricity companies is demand forecasting and stock management. The electric materials have following characters: (I) High significance, the operation of electricity company is closely linked with the daily life of the inhabitants that live around, once the company cannot provide electricity as usual, it will lead to enormous economic loss and the dissatisfied of the inhabitants. (II) High price level, 
the price of some electric materials is expensive even around millions. If company holds too many materials to keep the usual company operation and emergency maintenance, it will cause the capital shortage, the high inventory pressure and will lead to an enormous write-off cost of materials, influencing the overall company operation. (III) Long period in advance, some materials are difficult to produce with a high time and money cost. Therefore, it needs to be ordered in advance. If the order is made after a breakdown, it will make the company unable to work for a long time. (IV) Discontinuity of demand, the demand of electric materials is discontinuous, therefore it is hard to forecast demand correctly and efficiently control inventory. There is a lack of good management method that is generally accepted.

Intermittent demand is a kind of stochastic demand, while the demand data contains many zero value. Except continuous producing process, the demand of the majority of electric power materials is discontinuous (like recorded by hours, minutes, or whether there is a break off), however, most of them can convert to continuous demands. The conversion is significant for practical problems. For example, the sales of hours or minutes can be discontinuous, but it will be converted to be continuous if we record sales every day, week or month, which is significant to our problem. However, there are still many situations when intermittent demand can't be converted to continuous demand because the conversion makes the practical problem meaningless. For example, some materials is needed only once per year or per two years and the lead time of that kind of material is usually short like few days or a month, which results in the continuous demand meaningful. The material that has intermittent demand widely exist in our daily life, such as travel and luxury furniture consuming; valuable equipment marketing like machine tools, transportation tools and smelting equipment; spare parts that are used in productive process and transportation means like airplane, submarine and steamship. These materials consume slowly (low demand rate), the time interval between two needs is long. Therefore, many materials that are intermittent demand is significant in productive process, for example, luxury equipment, which occupies a lot of capital, the poor management of this kind of equipment will lead to a low capital turnover or frequently out of stock, which will negatively affect the efficiency of the company operation. Some materials that are intermittent demand like spare parts are essential in productive process, of which the shortage can lead to heavy loss. Take electricity materials as example, once suffered from shortage, the electricity company would not able to provide electricity as usual and will cause an enormous economic loss (even hundreds or thousands of million). In addition, some of the spare parts are difficult to produce and very expensive, therefore, an advance order is 
needed. If the order is made after the breakdown, it will make companies unable to operate for a long time, causing larger economic loss further.

Electricity spare parts that are discontinuous needed are very important in the productive process of electricity companies. Therefore, accurate forecast and stock control is needed. The existing theories of forecast and stock control assume that the demands are independent. However, Willemain, Smart, Shockor, and Desautels (1994) believes that actual data always show correlation, Magson (1979) points out their data of spare parts has a negative autocorrelation. Meanwhile, Eaves (2002) finds out that the spare parts data of Royal Air Force shows prominent correlation. According to the evidence, the assumption that the demand is independent may not be accurate for electric product. Therefore, the study on the effect of correlation of electric materials on forecast and stock control has significant importance.

\section{Research Background}

On account for the effect of correlation of continuous demand on forecast and stock control, Johnson and Thompson (1975) mentions that forecast in a short term would be ideal if the demand has autocorrelation. In addition, the autocorrelation will also affect safety stock. Several studies show that a positive autocorrelation will cause an overestimation of the safety stock, and a negative autocorrelation will lead to an underestimation of safety stock (Alrefaei, Andrad, ttir, \& Graves, 1999; Ray, 1980; Wang, 1987). Similarly, Miller (1986) points out that a positive autocorrelation will decrease maximum stock level. Fotopoulos, Wang, and Rao (1988) reaches the conclusion that positive autocorrelation will lead to a stronger effect on safety stock compared to negative autocorrelation; safety stock will increase with the increase of autocorrelation, vise-versa; when the autocorrelation is positive and increasing, the speed of the change of safety stock will increase. Erkip, Hausman, and Nahmias (1990) points out that positive self-correlation will increase the standard deviation during the lead time so that lead to a higher level of safety stock, while negative self-correlation will decrease the safety stock. However, these articles have not studied on the effect of correlation of intermittent demand on forecasting and stock control.

In the field of intermittent demand forecasting, Corston raised the first creative forecasting method in 1972. However, the method has been proved biased. Two articles present to use correlation factor to overcome the bias(Shale \& Johnston, 2006; A. A. Syntetos \& Croston, 2005) and other two articles prove the veracity with calculation examples(Aris A. Syntetos \& Boylan, 2005; Teunter \& Sani, 2009b). Levén and Segerstedt (2004) amend the Croston method by considering the length of interval of demand when smoothing the data of demand. Generally speaking, Syntetos-Boylan 
Approximation (SBA) method is identified to be the best amendment of Croston method. The present article mainly uses the Croston method with amendment, Bootstrap and simulating distribution method. Bootstraping is a uniform sampling with replacement from given training set, which means every sample that had been chose will be able to be chose twice and be added back to the training set. A sample chose from normal distributed population obeys normal distribution. However, when the population doesn't obey the normal distribution, the sample should be analyzed by evolving analysis method and Bootstraping method. Bootstraping does random sampling and is effective for small database, demand array that contains many zero values and conditions that the lead time is fixed. Meanwhile, this method is able to forecast whether there will be a demand in advance or not, give the probability and the amount of demand of every term, produce many demand sample after multiple repeats and finally get the distribution of the forecasting lead time. Nevertheless, Bootstrap method requires large sample size and a large number of previous statistical material to guarantee the accuracy of the forecast. The theoretical evidence (Porteus, 1985; Silver, Pyke, \& Peterson, 1998), the digital simulation (Babai, Jemai, \& Dallery, 2011; Sani \& Kingsman, 1997) and the case from Porras and Dekker (2008) conformably indicate that the (s, S) system is more proper. However, due to that intermittent demand has little nonzero value, which means it is hard to get accurate distribution of demand, therefore, we can't calculate out s and S; even the distribution is known, the calculation process of optimal (s, S) is complicated. Therefore, Sani and Kingsman (1997) does a contrast research on different form of $(\mathrm{T}, \mathrm{s}, \mathrm{S})$ calculating method, the result indicate that the Power Approximation method (Ehrhardt, 1979), Normal Approximation method (Wagner, 1975) and Naddor's heuristic method (Naddor, 1975) perform well in the stock control of intermittent demand and the difference of the three methods are small. Therefore, the three methods are widely agreed to be the best method that used to control discontinuous stock. Babai et al. (2011) do a similar study with a large amount of data and come up with the conclusion that Power Approximation method and Naddor's heuristic method are best in calculating average stock cost. Teunter and Sani (2009a) come up with the $(T, S)$ dynamic inventory strategy and sets up the maximum stock level model, the calculation result indicates that the model can get better service level. However, the previous studies for intermittent demand forecast and stock control don't cover the effect of statistic correlation on forecast and stock control. Eaves (2002) tests the effect of three correlation types (autocorrelation of demand, autocorrelation of demand interval and the cross-correlation of demand and demand interval) based on actual data on forecasting accuracy. The result suggests that when demand and demand interval are negatively correlated, forecast accuracy is 
the best. While, the study doesn't cover the effect of those three corrective types on stock control of intermittent demand. Although Altay, Litteral, and Rudisill (2012) study the effect of those three corrective types on stock control of intermittent demand, the data that used is simulated and empirical study is not taken.

\section{Project Design of the Effects of the Correlation on Forecasting and Stock Control}

In conclusion, this article will take empirical study on electricity spare parts needs data. First, judge whether electricity spare parts needs data has previous three correlation types. Then measure the effect of correlation on forecast by error precision, measuring the effect of correlation on forecast by the cross-correlation of average cost and average service level, the final result indicate that the correlation of electricity spare parts will obviously effect forecast and stock control. The conclusion gives some use of reference to more accurate forecasting method and decrease stock cost in the future.

This article considers the correlation of demand from three aspects: autocorrelation of demand, autocorrelation of demand intervals and crosscorrelation of demand and demand interval. Additionally, it also analyzes the effect on forecasting and stock control.

First, the authors calculate the average interval of demand, the variable coefficient of nonzero demand, autocorrelation of demand, autocorrelation of demand intervals and cross-correlation of demand and demand interval; then screen out data that have the same (similar) average demand interval (ADI) and coefficient of variation $\left(\mathrm{CV}^{2}\right)$ to avoid the effect of other factors (ADI and $\mathrm{CV}^{2}$ ) on forecast accuracy and stock control. However, due to that there are only a little amount of data that have the same $\mathrm{ADI}$ and $\mathrm{CV}^{2}$ among actual database, this article will fix the ADI first and observe the effect of $\mathrm{CV}^{2}$ and correlation coefficient on forecast accuracy and inventory control. At last, compare the effect under different ADI to see if there is any difference between them.

The process is shown in Figure 1.

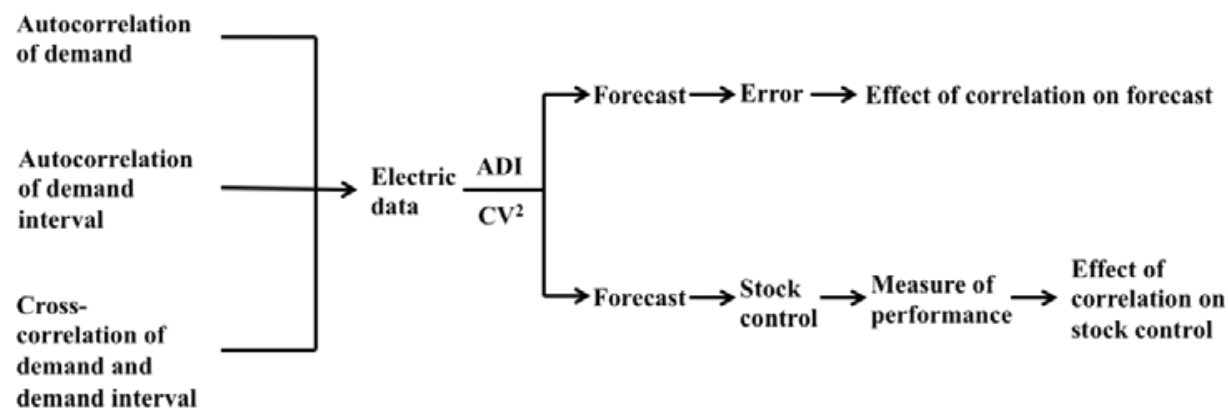

Figure 1. Project Structure 


\subsection{Forecast Method (SBA)}

To examine the effect of electricity spare parts correlation on the accuracy of forecast, this article chooses SBA method to forecast data since it is identified to be optimal amendment of Croston method. Meanwhile, it is widely agreed to be an efficient forecasting tool.

$$
\begin{gathered}
F_{t}=\left(1-\frac{a}{2}\right) \frac{Z_{t}}{p_{t}}(3-1) \\
Z_{t}=Z_{t-1}+a\left(D_{t}-Z_{t-1}\right)(3-2) \\
p_{t}=p_{t-1}+a\left(q_{t-1}-p_{t-q}\right)(3-3)
\end{gathered}
$$

In the functions, $D_{\mathrm{t}}$ is the actual demand of one product at time $\mathrm{t}, q_{t}$ is the actual demand interval at time $t, Z_{t}$ and $p_{t}$ is demand and demand interval at time t, $\alpha$ is the smoothness index.

\section{Stock Control Strategy (Dynamic Maximum Stock Strategy)}

To examine the effect of correlation of electricity spare parts on stock control, this article uses (T, S) dynamic stock strategy. The strategy is to replenish inventory to maximum inventory $S$ after every check on the premise of periodicity check, however, maximum inventory $S$ varies according to future demand. $\mathrm{S}$ is determined by three factors: future demand, inventory safety factors (expected service level) and the standard deviation of demand array. Through keeping maximum inventory $\mathrm{S}$ at a dynamic level, (T, S) dynamic inventory strategy can adjust inventory level according to future demand. Therefore, it can react well according to the change of demand without consume unnecessary capitals to decrease cost.

$$
\begin{gathered}
S=\hat{D}_{t}+k \hat{\sigma}_{t}(3-4) \\
\hat{\sigma}_{L}=\sqrt{\frac{\sum_{t=1}^{n}\left(\hat{\mathrm{D}}_{t}-\mathrm{D}_{t}\right)^{2}}{n-1}}
\end{gathered}
$$

In the functions, $D_{t}$ is the actual demand at time $t, \hat{D}_{t}$ is the expected demand in advance at time $\mathrm{t}, \mathrm{k}$ is the safety stock factor and $\hat{\sigma}_{\mathrm{L}}$ is the standard deviation of forecast error of advance period.

\section{Measurement Index}

Different forecast object has different characters, while different forecast methods have their own advantage and disadvantage. One of the most important tasks of forecast research is to select proper forecast method to obtain higher reliability level and accuracy level. Forecast accuracy means 
the quality of forecast model fitting, which is the degree of fitting of the forecast value by forecast model and the actual value of history. This article uses Relative Geometric Mean Absolute Error (RGMAE), Mean Absolute Scale Error (MASE) and Mean Absolute Percentage Error (MAPE). Among the three forecast accuracy indicators, MAPE is used to measure the effect of the autocorrelation of demand and autocorrelation of demand interval on forecasting accuracy, MASE and RGMAE are used to measure the correlation of demand and demand interval on forecast accuracy. RGAME is based on Single Exponential Smoothing (SES) to examine the forecast accuracy of SBA method. On contrast of the offset of MPE, this article chooses MAPE method. Meanwhile, MAPE method is more widely used and accepted than mean absolute deviation (MAD). MASE uses the standard deviation of the forecast error, which can multiply the error of every forecast error. Therefore, single forecast value that has big error could be multiplied to bigger error while small error won't be multiplied to that big. To conclude, the square of the forecast error can examine forecast accuracy better than MAPE and MAD methods.

\section{Inventory Objective}

The authors uses average service value (AvgSERV) and average cost (AvgCOST) to examine the quality of the inventory control.

$$
\begin{aligned}
& S E R V=\left\{\begin{array}{cc}
0 & D_{t}=0 \\
1 & \frac{A_{t}+Q_{t}}{D_{t}} \geq 1 \\
\frac{A_{t}+Q_{t}}{D_{t}} & 0<\frac{A_{t}+Q_{t}}{D_{t}}<1
\end{array}\right. \\
& \operatorname{AvgSERV}=\frac{\sum_{i=1}^{n} S E R V}{n}(3-7) \\
& \operatorname{COST}=H\left(A_{t}+Q_{t-1}-D_{t}\right)^{+}+B\left(D_{t}-A_{t}-Q_{t-1}\right)^{+}+K Q_{t}(3-8) \\
& \operatorname{AvgCOST}=\frac{\sum_{t=1}^{n} \operatorname{COST}}{n}(3-9)
\end{aligned}
$$

$A_{t}$ is the initial stock value at time $t, Q_{t}$ is the order value at time $t$, $D_{t}$ is the real demand value at time $t, H$ is the cost of stock, $B$ is the cost 
of stock out, $K$ is the ordering cost, $(\mathrm{X}-\mathrm{Y})^{+}=(\operatorname{IDax} \mathrm{X}-\mathrm{Y})$

\section{Predictive Index}

The calculation function of RGMAE is as follows. In this function, $F(\mathrm{~A})_{t}$ represents the result of the forecast of SBA method, $F(B)_{t}$ represents the result of the forecast of SES method, $D_{t}$ is the real demand at time t.

$$
R G M A E=\frac{\left(\prod_{t=1}^{n}\left|\mathrm{D}_{t}-F(\mathrm{~A})_{t}\right|\right)^{\frac{1}{n}}}{\left(\prod_{t=1}^{n}\left|\mathrm{D}_{t}-F(\mathrm{~B})_{\mathrm{t}}\right|\right)^{\frac{1}{n}}}(3-10)
$$

Furthermore, this article uses the un-scaled error measure MASE that is present by Hyndman in 2006. MASE is based on simple forecast algorithm to examine the forecast error. MASE is the average absolute value of SE.

$$
\begin{gathered}
S E_{t}=\frac{e_{t}}{\left(\frac{1}{n}-1\right) \sum_{t=2}^{n}\left|D_{t}-D_{t-1}\right|}(3-11) \\
M A S E=\frac{\sum_{t=1}^{n}\left|S E_{t}\right|}{n}(3-12)
\end{gathered}
$$

$e_{t}$ is the error of the forecast, $D_{t}$ is the real demand at time $t$ and $n$ is the length of demand in the history.

When examine the effect of autocorrelations of demand value and demand interval on forecast accuracy, this article uses mean absolute percentage error (MAPE). There are two reasons: (I) RGMAE can't examine the forecast accuracy in this test. This article uses Exponential Smoothing to predict the demand value and the demand interval, as consequence, value of RGMAE will be one. (II) Single demand array and demand interval array are consist of nonzero. The calculation function of MAPE is:

$$
\text { MAPE }=\frac{1}{\mathrm{n}} \sum_{t=1}^{n}\left|\frac{D_{\mathrm{t}}-F_{t}}{D_{t}}\right|(3-13)
$$

$D_{\mathrm{t}}$ is the real demand at time $\mathrm{t}$ and $F_{t}$ is the demand that predict by SBA method at time $t$.

\section{Empirical Analysis}

This article uses a database that includes the history data of 3839 kinds of electricity materials in 36 months (however, there are many materials that are sporadic needed, which means the number of requirement 
is under three in 36 months. Therefore, only 1040 kinds that have a certain number of requirements are chose), suppose the data of the first 24 months is historical data and the after 12 months is test data. Calculate the average demand interval, variable coefficient of nonzero demand value, autocorrelation index of demand, autocorrelation index demand interval and the correlation between demand and demand interval. When calculate the correlation between demand and demand interval, the data demand to do two pretreatment: (I) Due to that the length of the demand array and demand interval array aren't match, the first amount of every nonzero demand array is dislodged. (II) Due to the difference of dimensions of the demand array and the demand interval array, a normalization processing is done.

The autocorrelation of electricity spare parts demand and demand interval are positive, mostly between 0.2 and 0.6 . This means that electricity spare parts have positive autocorrelation. The correlation between electricity demand and demand interval is likely to be negative and the absolute value is small, mostly between -0.04 and 0.02 , which means electricity spare parts mainly show a negative and weaker correlation.

\section{Analysis about the Effect of Correlation on Forecast Accuracy The Expected Percentage of Acceptable SKU (Fixed ADI and Correlation Coefficient)}

Table 1. The Proportion of Predict Acceptable SKU (Autocorrelation of Demand)

\begin{tabular}{c|c|c|c|c|c|c|c|c|c}
\hline & \multicolumn{7}{|c}{ The range of autocorrelation of demand } & \\
\hline ADI & {$[-1,-0.4]$} & {$[-0.4,-0.2]$} & {$[-0.2,0]$} & {$[0,0.2]$} & {$[0.2,0.4]$} & {$[0.4,0.6]$} & {$[0.6,0.8]$} & {$[0.8,1]$} & Total \\
\hline $1-1.32$ & $0.00 \%$ & $62.50 \%$ & $70.00 \%$ & $61.90 \%$ & $74.79 \%$ & $74.07 \%$ & $72.00 \%$ & $0.00 \%$ & 275 \\
$1.32-3$ & $100.00 \%$ & $82.35 \%$ & $80.00 \%$ & $65.12 \%$ & $70.29 \%$ & $73.01 \%$ & $76.92 \%$ & $50.00 \%$ & 306 \\
$3-11$ & $0.00 \%$ & $85.71 \%$ & $81.82 \%$ & $80.95 \%$ & $76.09 \%$ & $82.89 \%$ & $72.41 \%$ & $0.00 \%$ & 186 \\
\hline Proportion & $100.00 \%$ & $75.00 \%$ & $76.09 \%$ & $66.98 \%$ & $73.35 \%$ & $75.40 \%$ & $73.73 \%$ & $50.00 \%$ & 767 \\
\hline Sum & 5 & 40 & 46 & 106 & 349 & 374 & 118 & 2 & 1040 \\
\hline
\end{tabular}




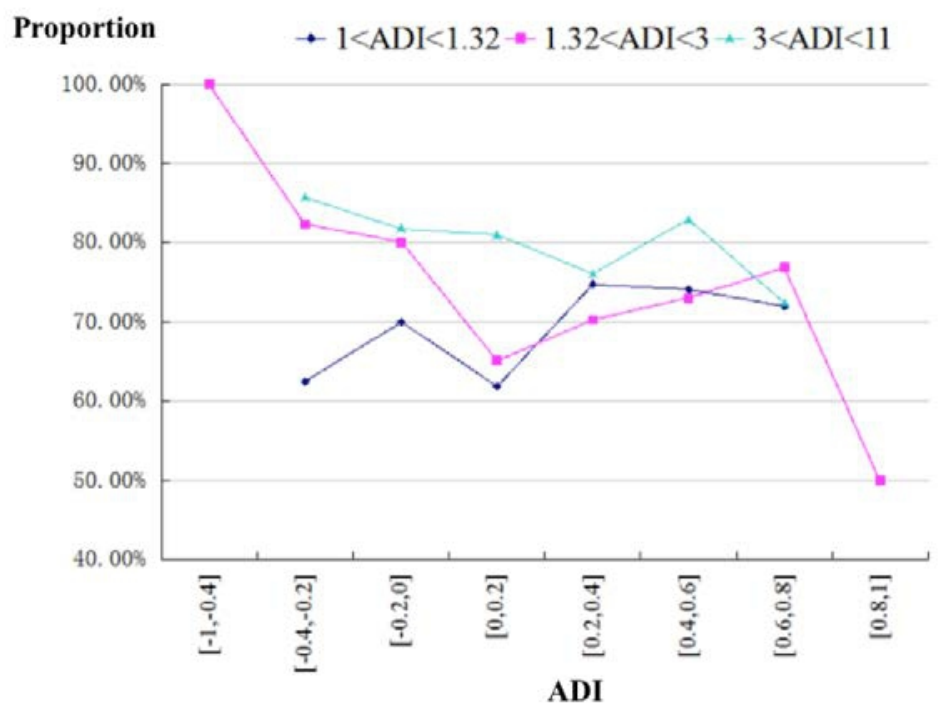

Figure 2. The Proportion of Predict Acceptable SKU

On account of the different value in different autocorrelation index interval, this article aims to observe the overall trend. Besides, Small ADI means that the demand is partial continuous. The acceptable percentage of predict result will increase according to the autocorrelation changes from negative to positive. For the value that has bigger ADI, which means intermittent demand, the acceptable percentage of predict result decrease according to the autocorrelation changes from negative to positive. When ADI is in $[1,1.32]$, which means the demand array is partial continuous, the forecast accuracy is the worst. Because this article uses exponential smoothing method and the average $\mathrm{CV}^{2}$ of data in the interval is 1.97 , the fluctuation is large. Therefore, the forecast result of exponential smoothing method isn't satisfied.

Table 2. Special Point Data

\begin{tabular}{ccc}
\hline Materials & 500065699 & 500059118 \\
\hline Subclass & Cable branch box & $\begin{array}{c}\text { Terminal connector - } \\
\text { screw-type }\end{array}$ \\
Autocorrelation of demand & 0.81412 & 0.813966 \\
Autocorrelation of demand interval & 0.540257 & 0.436568 \\
Cross-correlation of demand and & 0.011913 & -0.04609 \\
demand interval & 1.412821 & 0.377673 \\
Demand MAPE &
\end{tabular}


Table 3. The Proportion of Predict Acceptable SKU (Autocorrelation of Demand Interval)

\begin{tabular}{c|c|c|c|c|c|c|c|c}
\hline & \multicolumn{7}{|c|}{ The range of autocorrelation of demand interval } & \\
\hline ADI & {$[-1,-0.3]$} & {$[-0.3,-0.1]$} & {$[-0.1,0.1]$} & {$[0.1,0.3]$} & {$[0.3,0.5]$} & {$[0.5,0.7]$} & {$[0.7,1]$} & Total \\
\hline $1-1.32$ & $100.00 \%$ & $96.15 \%$ & $95.89 \%$ & $100.00 \%$ & $94.25 \%$ & $98.61 \%$ & $96.23 \%$ & 370 \\
$1.32-3$ & $0.00 \%$ & $66.67 \%$ & $84.00 \%$ & $91.80 \%$ & $93.59 \%$ & $96.00 \%$ & $100.00 \%$ & 397 \\
$3-11$ & $0.00 \%$ & $0.00 \%$ & $77.78 \%$ & $84.06 \%$ & $91.92 \%$ & $93.62 \%$ & $100.00 \%$ & 210 \\
\hline $\begin{array}{c}\text { Propo- } \\
\text { rtion }\end{array}$ & $100.00 \%$ & $93.10 \%$ & $92.55 \%$ & $88.65 \%$ & $93.27 \%$ & $96.26 \%$ & $95.00 \%$ & 977 \\
\hline Sum & 60 & 29 & 94 & 141 & 342 & 294 & 80 & 1040 \\
\hline
\end{tabular}

Figure 3. The Proportion of Predict Acceptable SKU

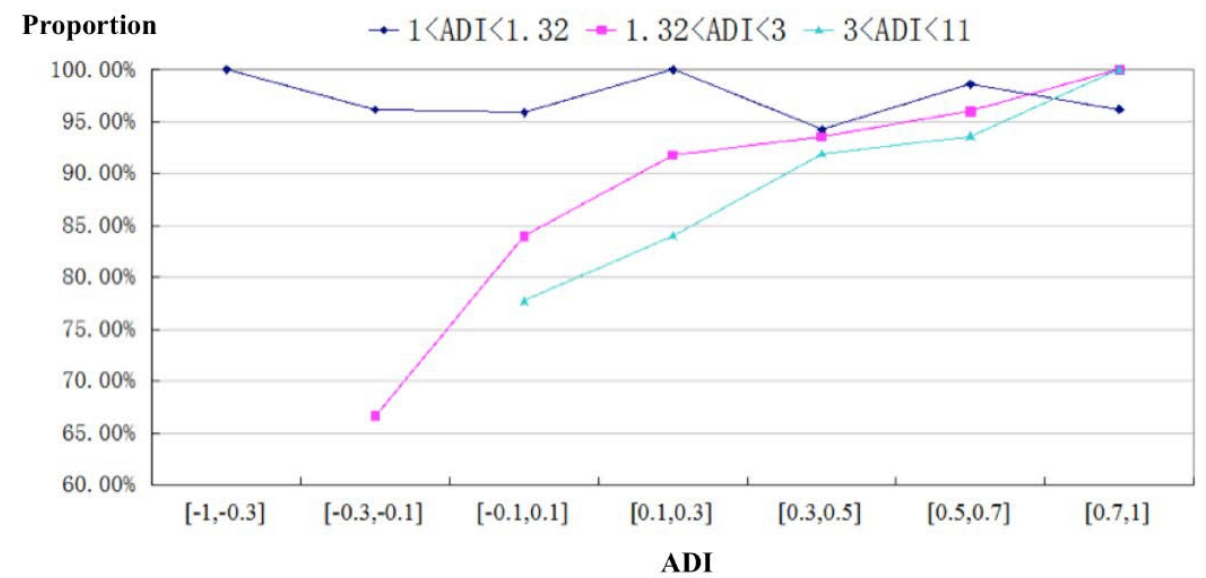

When ADI is between [1, 1.32], the demand array is partial continuous. Therefore, the impact of autocorrelation on the predict demand interval is not obvious and most of forecasting results are satisfactory. When ADI is between [1.32, 3], the percentages of value with high forecast accuracy get increased due to the change of autocorrelation from negative to positive. This indicates that the forecasting performance is significantly improved. Meanwhile, when the correlation index is negative, the predictive effect is worse. When ADI is between $[3,11]$, the percentages of value with high forecast accuracy increase according to the autocorrelation change from negative to positive, which also means that the predictive effect becomes better. In addition, the forecasting performance of the value is the worst at the same autocorrelation of demand interval.

Table 4. The Proportion of Predict Acceptable SKU (Cross-correlation of Demand and Demand Interval)

\begin{tabular}{|c|c|c|c|c|c|c|}
\hline \multirow[b]{2}{*}{ ADI } & \multicolumn{5}{|c|}{ The range of cross-correlation of demand and demand interval } & \multirow[b]{2}{*}{ Total } \\
\hline & {$[-1,-0.2]$} & {$[-0.2,-0.1]$} & {$[-0.1,0]$} & {$[0,0.1]$} & {$[0.1,1]$} & \\
\hline $1-1.32$ & $0.00 \%$ & $80.00 \%$ & $44.19 \%$ & $86.34 \%$ & $78.95 \%$ & 272 \\
\hline $1.32-3$ & $0.00 \%$ & $76.92 \%$ & $69.91 \%$ & $91.71 \%$ & $0.00 \%$ & 338 \\
\hline
\end{tabular}




\begin{tabular}{l|l|l|l|l|l|l}
$3-11$ & $0.00 \%$ & $0.00 \%$ & $62.44 \%$ & $79.49 \%$ & $0.00 \%$ & 154 \\
\hline Proportion & $0.00 \%$ & $77.78 \%$ & $61.07 \%$ & $88.02 \%$ & $78.95 \%$ & 764 \\
\hline Sum & 2 & 18 & 542 & 459 & 19 & 1040 \\
\hline
\end{tabular}

Figure 4. The Proportion of Predict Acceptable SKU

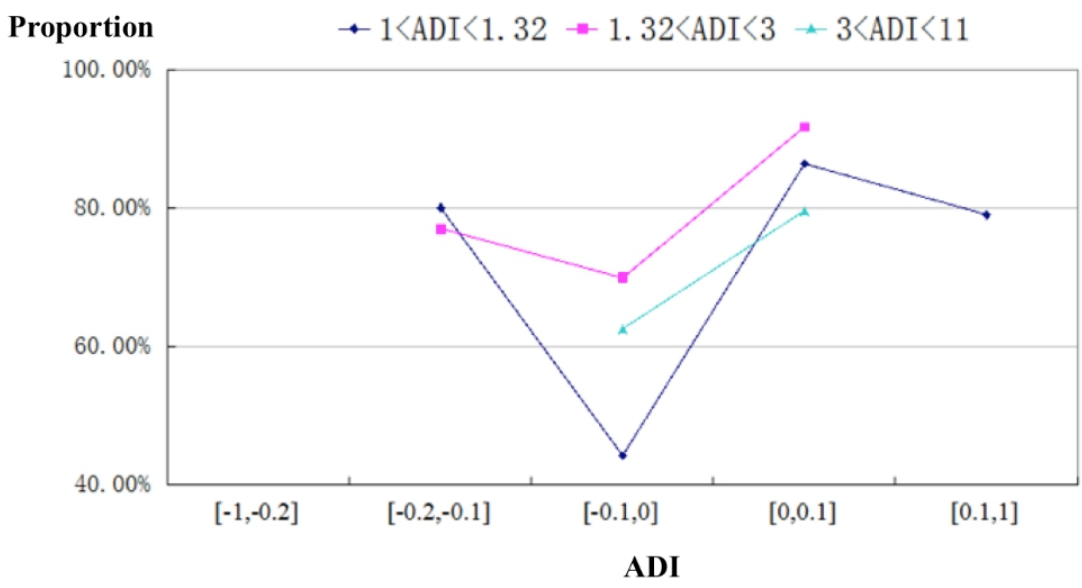

From the overall, the cross-correlation of the electricity data decreases with the increase of ADI. In addition, in the same range of ADI, when the cross-correlation of demand and demand interval is between [-0.1, $0]$, the predictive effect is the worst. The demand array is partial continuous when ADI is between [1,1.32], the predictive effect is poor because the SBA forecast method in this article doesn't fit for continuous value. In addition, when the cross-correlation of demand and demand interval is between [-0.1, $0]$, the forecasting performance is the worst.

\section{The Expected Percentage of Acceptable SKU (Same Range of Correlation Coefficient)}

Table 5. Prediction of Autocorrelation of Demand MAPE $<1$

In the demand forecasting, when the autocorrelation of the demand is between $[-1,-0.4]$, most of the ADI are in $[-0.4,-0.2]$ and the predictive effect is worse while most of the predictive accuracy is above 1 . When the autocorrelation of the demand is between $[-0.4,-0.2]$, most of the ADI are in $[1,3]$ and the predictive effect is satisfactory, not affected by ADI. When the autocorrelation of the demand is between $[-0.2,0.8]$, most of the ADI is in $[1,3]$ and the predictive effect is good in general, most of the predictive accuracy is below 1 . When the autocorrelation of the demand is between $[0.8,1]$, the predictive effect is not comparable because the value is rare in this interval. 
In general, when the autocorrelation of the demand is between [0.4, $0.6]$, the predictive effect is the best, while when the autocorrelation of the demand is between $[0,0.2]$, the predictive effect is the worst.

If a new product needs to be predicted and inventory controlled, the new product will have certain demands. Calculate the autocorrelation of the demand and the ADI, then compare to the data in the chart to estimate the predictive accuracy of demand. If the predictive accuracy is high, the forecast value can be directly used to control inventory; if the predictive accuracy is low, a new way should be found to control inventory.

Table 6. Prediction of Autocorrelation of Demand Interval MAPE $>1$

\begin{tabular}{c|c|c|c|c|c|c|c|c}
\hline & \multicolumn{7}{|c}{ The range of autocorrelation of demand interval } \\
\hline ADI & {$[-1,-0.3]$} & {$[-0.3,-0.1]$} & {$[-0.1,0.1]$} & {$[0.1,0.3]$} & {$[0.3,0.5]$} & {$[0.5,0.7]$} & {$[0.7,1]$} & Total \\
\hline $1-1.5$ & $0.00 \%$ & $50.00 \%$ & $42.86 \%$ & $0.00 \%$ & $39.13 \%$ & $18.18 \%$ & $50.00 \%$ & 17 \\
$1.5-2$ & $0.00 \%$ & $0.00 \%$ & $0.00 \%$ & $6.25 \%$ & $17.39 \%$ & $36.36 \%$ & $50.00 \%$ & 11 \\
$2-3$ & $0.00 \%$ & $50.00 \%$ & $0.00 \%$ & $25.00 \%$ & $8.70 \%$ & $18.18 \%$ & $0.00 \%$ & 9 \\
$3-4$ & $0.00 \%$ & $0.00 \%$ & $0.00 \%$ & $18.75 \%$ & $4.35 \%$ & $9.09 \%$ & $0.00 \%$ & 5 \\
$4-11$ & $0.00 \%$ & $0.00 \%$ & $57.14 \%$ & $50.00 \%$ & $30.43 \%$ & $18.18 \%$ & $0.00 \%$ & 21 \\
\hline Total & 0 & 2 & 7 & 16 & 23 & 11 & 4 & 63 \\
\hline
\end{tabular}

Table 7. Prediction of Autocorrelation of Demand Interval MAPE $<1$

\begin{tabular}{c|c|c|c|c|c|c|c|c}
\hline & \multicolumn{7}{|c|}{ The range of autocorrelation of demand interval } & \\
\hline ADI & {$[-1,-0.3]$} & {$[-0.3,-0.1]$} & {$[-0.1,0.1]$} & {$[0.1,0.3]$} & {$[0.3,0.5]$} & {$[0.5,0.7]$} & {$[0.7,1]$} & Total \\
\hline $1-1.5$ & $100.00 \%$ & $96.30 \%$ & $80.46 \%$ & $10.40 \%$ & $36.36 \%$ & $36.04 \%$ & $68.42 \%$ & 439 \\
$1.5-2$ & $0.00 \%$ & $3.70 \%$ & $1.15 \%$ & $13.60 \%$ & $16.61 \%$ & $18.73 \%$ & $15.79 \%$ & 137 \\
$2-3$ & $0.00 \%$ & $0.00 \%$ & $2.30 \%$ & $24.80 \%$ & $15.36 \%$ & $27.21 \%$ & $10.53 \%$ & 167 \\
$3-4$ & $0.00 \%$ & $0.00 \%$ & $2.30 \%$ & $17.60 \%$ & $13.17 \%$ & $11.66 \%$ & $3.95 \%$ & 102 \\
$4-11$ & $0.00 \%$ & $0.00 \%$ & $13.79 \%$ & $33.60 \%$ & $18.50 \%$ & $6.36 \%$ & $1.32 \%$ & 132 \\
\hline Total & 60 & 27 & 87 & 125 & 319 & 283 & 76 & 977 \\
\hline
\end{tabular}

In the forecasting of the demand interval, when the autocorrelation of the demand interval is in [-1, -0.3$]$, all the ADIs are in $[1,1.5]$ and all the predictive effects are excellent. When the autocorrelation of the demand interval is in $[-0.3,0.1]$, most of the ADIs are in $[1,1.5]$ while the predictive effects are good. When the autocorrelation of the demand interval is in [-0.1, $0.3]$, most of the ADI is in $[2,11]$ while the predictive effects are good. When the autocorrelation of the demand interval is in [0.3, 0.5], ADI is scattered distribute in $[1,11]$ with every interval of ADI has some product, while the predictive effects are good. When the autocorrelation of the demand interval is in $[0.5,1]$, most of the ADI is in $[1,3]$, while the predictive effects are good. 
In general, when the autocorrelation of the demand interval is in [-1, 0.3 , the predictive accuracy of demand interval is the best; when the autocorrelation of the demand interval is in $[0.1,0.3]$, the predictive accuracy of demand interval is the worst.

If a new product needs to be predicted and inventory controlled, the new product will have certain demands. Calculate the autocorrelation of the demand and the ADI, then compare to the data in the chart to estimate the predictive accuracy of demand. If the predictive accuracy is high, the forecast value can be directly used to control inventory; if the predictive accuracy is low, a new way should be found to control inventory.

Table 8. Prediction of Cross-correlation MASE $>1$

\begin{tabular}{c|c|c|c|c|c|c}
\hline & \multicolumn{5}{|c|}{ The range of cross-correlation } & \\
\hline ADI & {$[-1,-0.2]$} & {$[-0.2,-0.1]$} & {$[-0.1,0]$} & {$[0,0.1]$} & {$[0.1,1]$} & Total \\
\hline $1-1.5$ & $100.00 \%$ & $75.00 \%$ & $33.85 \%$ & $52.27 \%$ & $100.00 \%$ & 121 \\
$1.5-2$ & $0.00 \%$ & $0.00 \%$ & $12.50 \%$ & $15.91 \%$ & $0.00 \%$ & 38 \\
$2-3$ & $0.00 \%$ & $25.00 \%$ & $15.10 \%$ & $13.64 \%$ & $0.00 \%$ & 42 \\
$3-4$ & $0.00 \%$ & $0.00 \%$ & $13.54 \%$ & $6.82 \%$ & $0.00 \%$ & 32 \\
$4-11$ & $0.00 \%$ & $0.00 \%$ & $25.00 \%$ & $11.36 \%$ & $0.00 \%$ & 58 \\
\hline Total & 2 & 4 & 192 & 88 & 5 & 291 \\
\hline
\end{tabular}

In the forecast of SBA method, the MASE index regards to the standard of the predictive accuracy estimate. When the cross-correlation of demand and demand interval is in [-1, -0.2], there are rarely amount of data, while the predictive effects are all bad; when the cross-correlation of demand and demand interval is in [-0.2, -0.1], all ADI is in [1, 3], most of the predictive effect are satisfactory; when the cross-correlation of demand and demand interval is in $[-0.1,0]$, all ADI is in [1, 3], most of the predictive effect are good, however, a certain parts of data shows a bad predictive effect; when the cross-correlation of demand and demand interval is in [0, $0.1]$, all ADI is in [1, 2], most of the predictive effect are good; when the cross-correlation of demand and demand interval is in [0.1, 0.2], all ADI is in $[1,1.5]$, most of the predictive effect are good.

In general, using MASE as measurement index, when the crosscorrelation of demand and demand interval is in $[0,0.1]$, the forecast effect of SBA is the best; when the cross-correlation of demand and demand interval is in $[-0.1,0]$, the forecast effect of SBA is the worst.

Table 9. Prediction of Cross-correlation MASE $<1$

\begin{tabular}{c|c|c|c|c|c|c}
\hline & \multicolumn{5}{|c}{ The range of cross-correlation } & \\
\hline ADI & {$[-1,-0.2]$} & {$[-0.2,-0.1]$} & {$[-0.1,0]$} & {$[0,0.1]$} & {$[0.1,1]$} & Total \\
\hline $1-1.5$ & $0.00 \%$ & $42.86 \%$ & $25.71 \%$ & $60.65 \%$ & $100.00 \%$ & 335 \\
\hline
\end{tabular}




\begin{tabular}{c|c|c|c|c|c|c}
\hline $1.5-2$ & $0.00 \%$ & $28.57 \%$ & $10.86 \%$ & $18.33 \%$ & $0.00 \%$ & 110 \\
$2-3$ & $0.00 \%$ & $28.57 \%$ & $22.86 \%$ & $13.48 \%$ & $0.00 \%$ & 134 \\
$3-4$ & $0.00 \%$ & $0.00 \%$ & $14.86 \%$ & $6.20 \%$ & $0.00 \%$ & 75 \\
$4-11$ & $0.00 \%$ & $0.00 \%$ & $25.71 \%$ & $1.35 \%$ & $0.00 \%$ & 95 \\
\hline Total & 0 & 14 & 350 & 371 & 14 & 749 \\
\hline
\end{tabular}

Table 10. Prediction of Cross-correlation RGMAE $>1$

\begin{tabular}{c|c|c|c|c|c|c}
\hline & \multicolumn{5}{|c|}{ The range of cross-correlation } & \\
\hline ADI & {$[-1,-0.2]$} & {$[-0.2,-0.1]$} & {$[-0.1,0]$} & {$[0,0.1]$} & {$[0.1,1]$} & Total \\
\hline $1-1.5$ & $100.00 \%$ & $50.00 \%$ & $38.86 \%$ & $61.82 \%$ & $100.00 \%$ & 124 \\
$1.5-2$ & $0.00 \%$ & $25.00 \%$ & $10.90 \%$ & $14.55 \%$ & $0.00 \%$ & 32 \\
$2-3$ & $0.00 \%$ & $25.00 \%$ & $11.85 \%$ & $9.09 \%$ & $0.00 \%$ & 31 \\
$3-4$ & $0.00 \%$ & $0.00 \%$ & $14.22 \%$ & $3.64 \%$ & $0.00 \%$ & 32 \\
$4-11$ & $0.00 \%$ & $0.00 \%$ & $24.17 \%$ & $10.91 \%$ & $0.00 \%$ & 57 \\
\hline Total & 2 & 4 & 211 & 55 & 4 & 276 \\
\hline
\end{tabular}

Table 11. Prediction of Cross-correlation RGMAE $<1$

\begin{tabular}{c|c|c|c|c|c|c}
\hline & \multicolumn{5}{|c|}{ The range of cross-correlation } & \\
\hline ADI & {$[-1,-0.2]$} & {$[-0.2,-0.1]$} & {$[-0.1,0]$} & {$[0,0.1]$} & {$[0.1,1]$} & Total \\
\hline $1-1.5$ & $0.00 \%$ & $50.00 \%$ & $22.05 \%$ & $58.66 \%$ & $100.00 \%$ & 332 \\
$1.5-2$ & $0.00 \%$ & $21.43 \%$ & $11.78 \%$ & $18.32 \%$ & $0.00 \%$ & 116 \\
$2-3$ & $0.00 \%$ & $28.57 \%$ & $25.38 \%$ & $14.11 \%$ & $0.00 \%$ & 145 \\
$3-4$ & $0.00 \%$ & $0.00 \%$ & $14.50 \%$ & $6.68 \%$ & $0.00 \%$ & 75 \\
$4-11$ & $0.00 \%$ & $0.00 \%$ & $26.28 \%$ & $2.23 \%$ & $0.00 \%$ & 96 \\
\hline Total & 0 & 14 & 331 & 404 & 15 & 764 \\
\hline
\end{tabular}

In the forecast of SBA method, the MASE index regards to the standard of the predictive accuracy estimate. When the cross-correlation of demand and demand interval is in [-1, -0.2], there are rarely amount of data, while the predictive effects are all bad; when the cross-correlation of demand and demand interval is in [-0.2, -0.1], all ADI is in [1, 3], most of the predictive effect are good; when the cross-correlation of demand and demand interval is in [-0.1, 0], all ADI is in [1, 3], most of the predictive effect are good, however, there are a certain parts of data doesn't have a good predictive effect; when the cross-correlation of demand and demand interval is in $[0,0.1]$, all $\mathrm{ADI}$ is in $[1,2]$, most of the predictive effect are good; when the cross-correlation of demand and demand interval is in [0.1, 0.2], all ADI is in $[1,1.5]$, most of the predictive effect are good. 
In general, using RGMAE as measurement index, when the crosscorrelation of demand and demand interval is in $[0,0.1]$, the forecast effect of SBA is the best; when the cross-correlation of demand and demand interval is in $[-0.1,0]$, the forecast effect of SBA is the worst.

Regardless using MASE or RGMAE as measurement index, in general, the regular pattern that shows from the data is the same, which means the regular pattern does exist, rather than an accidental regular pattern.

With respect to the demand forecasting and inventory control of a new material, the first step is calculating the autocorrelation of the demand and the ADI, then comparing to the data in the chart to estimate the forecasting accuracy of demand. If the forecasting accuracy is high, the forecast value can be directly used to control inventory; if the predictive accuracy is low, a new way should be found to control inventory.

\section{The Proportion of Subclass that Has Good Forecast Effect}

Table 12. Prediction of Autocorrelation of Subclass Demand (MAPE)

\begin{tabular}{|c|c|c|}
\hline Subclass & $\begin{array}{c}\text { The proportion of } \\
\text { MAPE }<1\end{array}$ & Total \\
\hline Middle connector of power cable $(\leq 35 \mathrm{kV})$ & $69.57 \%$ & 23 \\
\hline Cable terminal $(\leq 35 \mathrm{kV})$ & $75.61 \%$ & 41 \\
\hline Semicircle hoop & $82.35 \%$ & 34 \\
\hline Cotton covered wire & $75.00 \%$ & 24 \\
\hline Complete hoop & $73.33 \%$ & 15 \\
\hline Low tension switch & $76.47 \%$ & 17 \\
\hline Low voltage fuse & $92.86 \%$ & 14 \\
\hline Low voltage fuse parts & $81.25 \%$ & 16 \\
\hline Cable protection pipe & $76.92 \%$ & 13 \\
\hline Wire hoop & $78.95 \%$ & 19 \\
\hline Cable terminal & $61.90 \%$ & 21 \\
\hline Ground rod & $66.67 \%$ & 12 \\
\hline Connection hardware - Insulation piercing connectors & $60.00 \%$ & 10 \\
\hline Insulated shield & $81.82 \%$ & 11 \\
\hline Screwdriver & $91.67 \%$ & 12 \\
\hline Strain clamp - Wedge insulation & $73.33 \%$ & 15 \\
\hline Plain bolt & $78.85 \%$ & 52 \\
\hline Safety fuse & $70.00 \%$ & 10 \\
\hline Equipment fixing support & $91.30 \%$ & 23 \\
\hline Cement materials & $81.82 \%$ & 11 \\
\hline
\end{tabular}




\begin{tabular}{c|c|c}
\hline Line angle of cross arm & $60.00 \%$ & 35 \\
Conical cement rod & $71.74 \%$ & 46 \\
\hline
\end{tabular}

The data in Table 12 satisfies two conditions; total demand is over 10 and the percentage of good performance of the demand is above $60 \%$. The demand forecasting of those materials performs well under different ADI and autocorrelation of demand. Specifically, the percentage of well-performed data is above $70 \%$. Therefore, for those kinds of demand, the predictive value can be used to control inventory and calculate cost in terms of demand.

Table 13. Prediction of Autocorrelation of Subclass Demand Interval (MAPE)

\begin{tabular}{|c|c|c|}
\hline Subclass & The proportion of MAPE $<1$ & Total \\
\hline Transformer (10kV) & $88.24 \%$ & 17 \\
\hline $\begin{array}{l}\text { Middle connector of power } \\
\text { cable }(\leq 35 \mathrm{kV})\end{array}$ & $100.00 \%$ & 23 \\
\hline Cable terminal $(\leq 35 \mathrm{kV})$ & $97.56 \%$ & 41 \\
\hline Semicircle hoop & $97.06 \%$ & 34 \\
\hline Cotton covered wire & $83.33 \%$ & 24 \\
\hline Complete hoop & $93.33 \%$ & 15 \\
\hline Low tension switch & $100.00 \%$ & 17 \\
\hline Low voltage fuse & $100.00 \%$ & 14 \\
\hline Low voltage fuse parts & $100.00 \%$ & 16 \\
\hline Cable protection pipe & $92.31 \%$ & 13 \\
\hline Wire hoop & $100.00 \%$ & 19 \\
\hline Cable terminal & $100.00 \%$ & 21 \\
\hline JKLYJ & $100.00 \%$ & 28 \\
\hline Ground rod & $83.33 \%$ & 12 \\
\hline $\begin{array}{c}\text { Connection hardware - } \\
\text { Insulation piercing connectors }\end{array}$ & $100.00 \%$ & 10 \\
\hline Insulated shield & $100.00 \%$ & 11 \\
\hline Screwdriver & $91.67 \%$ & 12 \\
\hline $\begin{array}{c}\text { Strain clamp - Wedge } \\
\text { insulation }\end{array}$ & $100.00 \%$ & 15 \\
\hline Plain bolt & $98.08 \%$ & 52 \\
\hline Safety fuse & $100.00 \%$ & 10 \\
\hline Equipment fixing support & $100.00 \%$ & 23 \\
\hline Cement materials & $100.00 \%$ & 11 \\
\hline Line angle of cross arm & $97.14 \%$ & 35 \\
\hline Conical cement rod & $86.96 \%$ & 46 \\
\hline
\end{tabular}


The data from Table 13 satisfies two conditions; the total demand is over 10 and the percentage of well forecasting performance is above $60 \%$. The demand forecasting of those materials performs well with respect to different ADI and autocorrelation of demand, of which the percentage of well-performed data is above $90 \%$ and many of the product forecasts are excellent. Therefore, for those kinds of demand, the predictive value can be used to control inventory and calculate relating cost.

Table 14. Prediction of Cross-correlation of Subclass Demand and Demand Interval (MAPE)

\begin{tabular}{|c|c|c|}
\hline Subclass & The proportion of MASE $<1$ & Total \\
\hline Transformer (10kV) & $70.59 \%$ & 17 \\
\hline $\begin{array}{l}\text { Middle connector of power } \\
\text { cable }(\leq 35 \mathrm{kV})\end{array}$ & $78.26 \%$ & 23 \\
\hline Cable terminal $(\leq 35 \mathrm{kV})$ & $68.29 \%$ & 41 \\
\hline Semicircle hoop & $85.29 \%$ & 34 \\
\hline Cotton covered wire & $75.00 \%$ & 24 \\
\hline Complete hoop & $73.33 \%$ & 15 \\
\hline Low tension switch & $70.59 \%$ & 17 \\
\hline Low voltage fuse & $85.71 \%$ & 14 \\
\hline Low voltage fuse parts & $62.50 \%$ & 16 \\
\hline Cable protection pipe & $76.92 \%$ & 13 \\
\hline Wire hoop & $78.95 \%$ & 19 \\
\hline Cable terminal & $90.48 \%$ & 21 \\
\hline JKLYJ & $75.00 \%$ & 28 \\
\hline Ground rod & $75.00 \%$ & 12 \\
\hline $\begin{array}{l}\text { Connection hardware - } \\
\text { Insulation piercing connectors }\end{array}$ & $80.00 \%$ & 10 \\
\hline Insulated shield & $90.91 \%$ & 11 \\
\hline $\begin{array}{l}\text { Strain clamp - Wedge } \\
\text { insulation }\end{array}$ & $66.67 \%$ & 15 \\
\hline Plain bolt & $76.92 \%$ & 52 \\
\hline Safety fuse & $90.00 \%$ & 10 \\
\hline Equipment fixing support & $78.26 \%$ & 23 \\
\hline Cement materials & $90.91 \%$ & 11 \\
\hline Line angle of cross arm & $65.71 \%$ & 35 \\
\hline Conical cement rod & $65.22 \%$ & 46 \\
\hline
\end{tabular}

The data from Table 14 satisfies two conditions; the total demand is over 10 and the percentage of good performance of SBA method (use MASE as measurement standard) is above $60 \%$. The demand forecasting of those 
materials performs well with respect to different ADI and autocorrelation of demand, of which the percentage of well-performed data is above $70 \%$. Therefore, for those kinds of demand, the predictive value can be used to control inventory and calculate relating cost.

Table 15. Prediction of Cross-correlation of Subclass Demand and Demand Interval (RGMAE)

\begin{tabular}{|c|c|c|}
\hline Subclass & The proportion of RGMAE $<1$ & Total \\
\hline Transformer (10kV) & $70.59 \%$ & 17 \\
\hline $\begin{array}{l}\text { Middle connector of power } \\
\text { cable }(\leq 35 \mathrm{kV})\end{array}$ & $78.26 \%$ & 23 \\
\hline Cable terminal $(\leq 35 \mathrm{kV})$ & $68.29 \%$ & 41 \\
\hline Semicircle hoop & $85.29 \%$ & 34 \\
\hline Cotton covered wire & $75.00 \%$ & 24 \\
\hline Complete hoop & $73.33 \%$ & 15 \\
\hline Low tension switch & $70.59 \%$ & 17 \\
\hline Low voltage fuse & $85.71 \%$ & 14 \\
\hline Low voltage fuse parts & $62.50 \%$ & 16 \\
\hline Cable protection pipe & $76.92 \%$ & 13 \\
\hline Wire hoop & $78.95 \%$ & 19 \\
\hline Cable terminal & $90.48 \%$ & 21 \\
\hline JKLYJ & $75.00 \%$ & 28 \\
\hline Ground rod & $75.00 \%$ & 12 \\
\hline $\begin{array}{c}\text { Connection hardware - } \\
\text { Insulation piercing connectors }\end{array}$ & $80.00 \%$ & 10 \\
\hline Insulated shield & $90.91 \%$ & 11 \\
\hline $\begin{array}{c}\text { Strain clamp - Wedge } \\
\text { insulation }\end{array}$ & $66.67 \%$ & 15 \\
\hline Plain bolt & $76.92 \%$ & 52 \\
\hline Safety fuse & $90.00 \%$ & 10 \\
\hline Equipment fixing support & $78.26 \%$ & 23 \\
\hline Cement materials & $90.91 \%$ & 11 \\
\hline Line angle of cross arm & $65.71 \%$ & 35 \\
\hline Conical cement rod & $65.22 \%$ & 46 \\
\hline
\end{tabular}

The data from Table 15 satisfies two conditions; one is that the total demand over 10 and the other is that the percentage of good performance of SBA method (use RGMAE as measurement standard) is above 60\%. The demand forecasting of those materials performs well with respect to different ADI and autocorrelation of demand, of which the percentage of well- 
performed data is above $70 \%$. Therefore, for those kinds of demand, the predictive value can be used to control inventory and calculate relating cost.

\section{Analysis of the Effect of Correlation on Stock Control}

To make calculation easier, suppose that demand and order both happen at the start of the month and the shortage of last month should be completed. This article also suppose that the stockholding cost $\mathrm{H}=1$, shortage cost $\mathrm{B}=10$ and ordering cost $\mathrm{K}=0.5$ to avoid the effect of single price on inventory calculation (cause the prices vary widely, it will not be able to do the comparison considering the price). In addition, put the calculation result under normalization processing to avoid the effect of demand amount on comparison of the data. Therefore, the inventory value that his article calculates out only can be used in comparison rather than the real amount of inventory cost. Assume the origin inventory as the maximum inventory level. In general, the average service level (AvgSER) decreases with the increase of ADI.

\section{Comparison of Average Cost}

Table 16. Average Cost (Autocorrelation of Demand)

\begin{tabular}{c|c|c|c|c|c|c|c|c|c}
\hline & \multicolumn{7}{|c|}{ The range of autocorrelation of demand } & \\
\hline ADI & {$[-1,-0.4]$} & {$[-0.4,-0.2]$} & {$[-0.2,0]$} & {$[0,0.2]$} & {$[0.2,0.4]$} & {$[0.4,0.6]$} & {$[0.6,0.8]$} & {$[0.8,1]$} & Total \\
\hline $1-1.5$ & 0.00 & 1.18 & 1.14 & 1.21 & 1.18 & 1.17 & 1.18 & 0.00 & 1.18 \\
$1.5-3$ & 1.23 & 1.28 & 1.14 & 1.33 & 1.35 & 1.32 & 1.32 & 2.15 & 1.33 \\
$3-11$ & 0.00 & 1.39 & 1.39 & 1.35 & 1.39 & 1.46 & 1.33 & 0.00 & 1.41 \\
\hline Total & 1.23 & 1.25 & 1.20 & 1.28 & 1.30 & 1.30 & 1.26 & 2.15 & 1.29 \\
\hline
\end{tabular}

Figure 5. Average Cost (Autocorrelation of Demand)

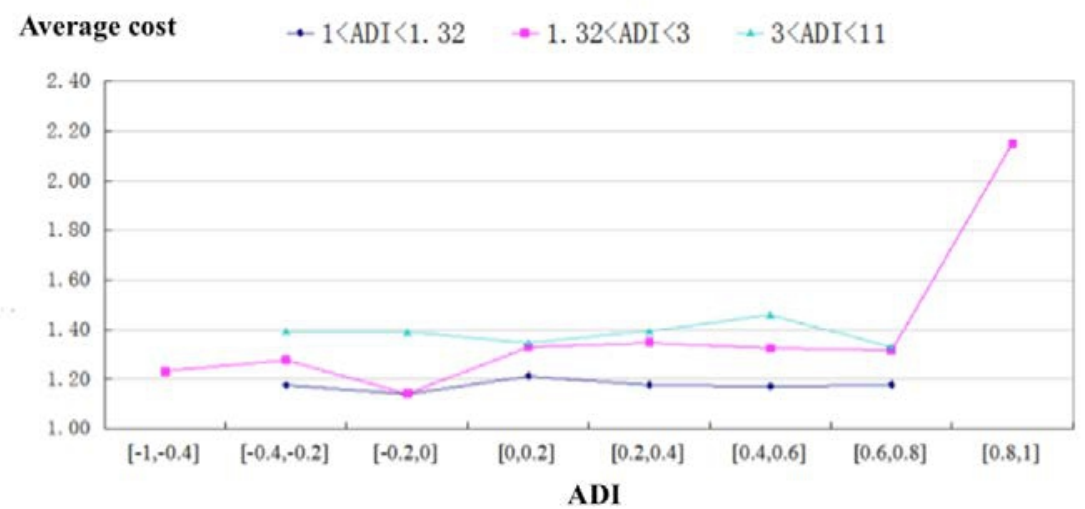

In general, the average cost of electricity materials will increase along with the increasing ADI. When ADI is in [1.32, 3] and the autocorrelation belongs to $[0.8,1]$, there will be abnormal value. As a result 
of the high $\mathrm{CV}^{2}$ of the demand of the electricity materials, the average cost is high.

Table 17. Average Cost (Autocorrelation of Demand Interval)

\begin{tabular}{c|c|c|c|c|c|c|c|c}
\hline & \multicolumn{7}{|c|}{ The range of autocorrelation of demand interval } & \\
\hline ADI & {$[-1,-0.3]$} & {$[-0.3,-0.1]$} & {$[-0.1,0.1]$} & {$[0.1,0.3]$} & {$[0.3,0.5]$} & {$[0.5,0.7]$} & {$[0.7,1]$} & Total \\
\hline $1-1.5$ & 1.09 & 1.11 & 1.07 & 0.97 & 1.31 & 1.19 & 1.32 & 1.18 \\
$1.5-3$ & 0.00 & 1.96 & 1.77 & 1.33 & 1.32 & 1.33 & 1.26 & 1.33 \\
$3-11$ & 0.00 & 0.00 & 1.35 & 1.48 & 1.39 & 1.38 & 1.41 & 1.41 \\
\hline Total & 1.09 & 1.17 & 1.14 & 1.35 & 1.34 & 1.30 & 1.30 & 1.29 \\
\hline
\end{tabular}

Figure 6. Average Cost (Autocorrelation of Demand Interval)

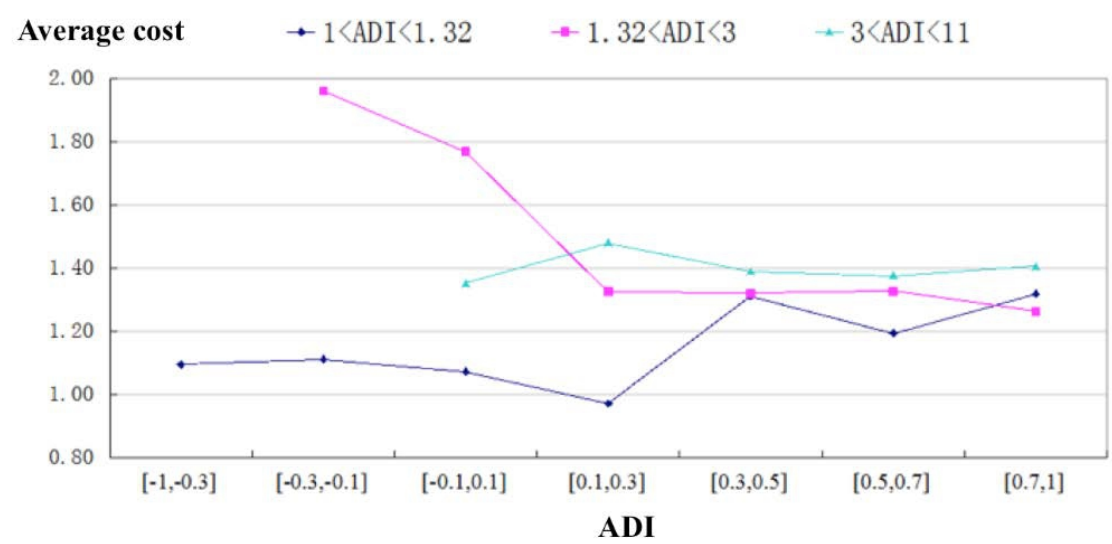

In general, the average cost of electricity materials will increase along with the increasing ADI. When ADI is in [1.32, 3] and the autocorrelation of the demand interval belongs to $[-0.3,-0.1]$, the $\mathrm{CV}^{2}$ of the electricity materials will be significantly high, leading to a sharply rises of the average cost; When ADI is in [1.32, 3] and the autocorrelation of the demand interval belongs to $[-0.1,0.1]$, the $\mathrm{CV}^{2}$ of the electricity materials will also be significantly high, leading to a modest rise of the average cost. Therefore, the average cost in those two autocorrelation intervals of demand interval exceeds other electricity materials that in other ADI range.

Table 18. Average Cost (Cross-correlation of Demand and Demand Interval)

\begin{tabular}{|c|c|c|c|c|c|c|}
\hline & \multicolumn{5}{|c|}{ The range of cross-correlation of demand and demand interval } & \multirow[b]{2}{*}{ Total } \\
\hline ADI & {$[-1,-0.2]$} & {$[-0.2,-0.1]$} & {$[-0.1,0]$} & {$[0,0.1]$} & {$[0.1,1]$} & \\
\hline $1-1.5$ & 1.26 & 1.13 & 1.30 & 1.13 & 1.09 & 1.18 \\
\hline $1.5-3$ & 0.00 & 1.18 & 1.34 & 1.32 & 0.00 & 1.33 \\
\hline $3-11$ & 0.00 & 0.00 & 1.42 & 1.36 & 0.00 & 1.41 \\
\hline Total & 1.26 & 1.17 & 1.36 & 1.23 & 1.09 & 1.29 \\
\hline
\end{tabular}


Figure 7. Average Cost (Cross-correlation of Demand and Demand Interval)

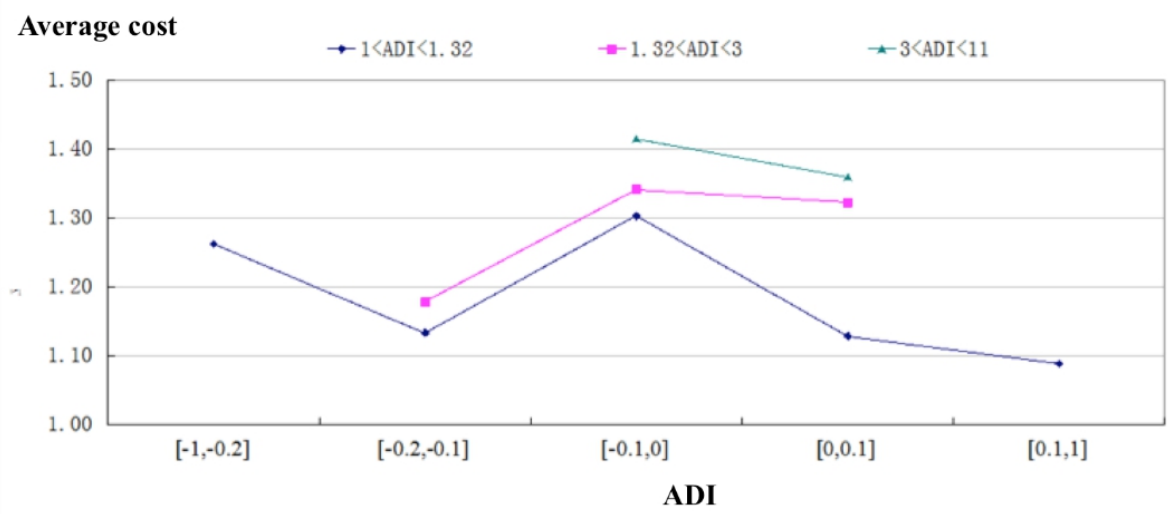

Under the condition that the ADI is the same and the crosscorrelation between demand and demand interval belongs to [-0.1, 0], the average cost is the highest. Meanwhile, when the cross-correlation of demand and demand interval belongs to $[-0.1,1]$, the average cost decrease with the increase of the cross-correlation.

\section{Comparison of Average Service Level}

In general, with an increasing of ADI, the average service level (AvgSER) of the electricity materials is decreasing.

Table 19. Average Service Level (Autocorrelation of Demand)

\begin{tabular}{c|c|c|c|c|c|c|c|c|c|c}
\hline & \multicolumn{7}{|c|}{ The range of autocorrelation of demand } & \\
\hline ADI & {$[-1,-0.4]$} & {$[-0.4,-0.2]$} & {$[-0.2,0]$} & {$[0,0.2]$} & {$[0.2,0.4]$} & {$[0.4,0.6]$} & {$[0.6,0.8]$} & {$[0.8,1]$} & Total \\
\hline $1-1.5$ & 0.00 & 0.93 & 0.97 & 0.97 & 0.97 & 0.96 & 0.97 & 0.00 & 0.97 \\
$1.5-3$ & 0.93 & 0.92 & 0.94 & 0.93 & 0.91 & 0.92 & 0.94 & 0.75 & 0.92 \\
$3-11$ & 0.00 & 0.73 & 0.78 & 0.76 & 0.81 & 0.78 & 0.84 & 0.00 & 0.80 \\
\hline Total & 0.93 & 0.90 & 0.92 & 0.92 & 0.91 & 0.91 & 0.93 & 0.75 & 0.91 \\
\hline
\end{tabular}

Figure 8. Average Service Level (Autocorrelation of Demand)

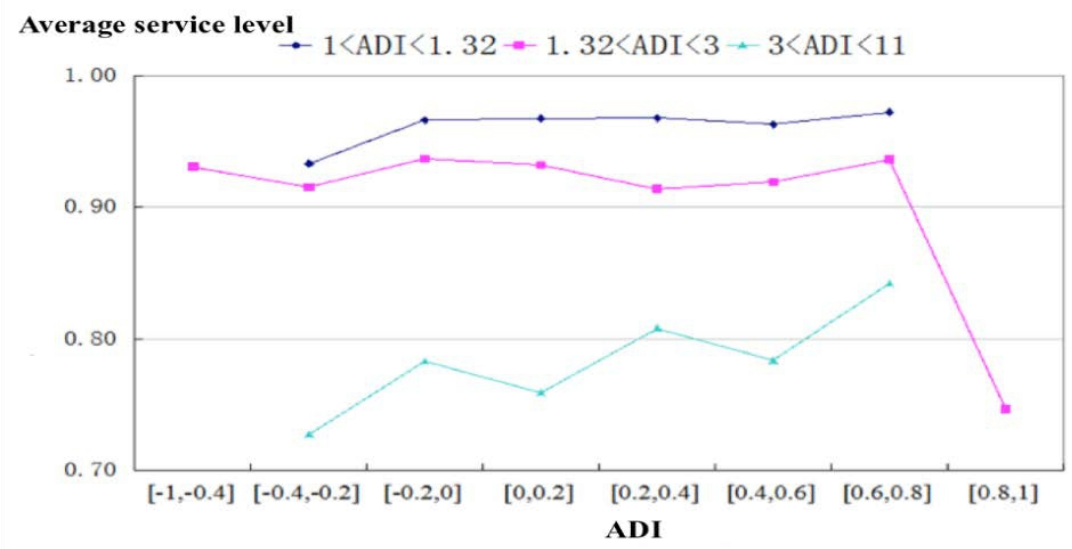


In general, average service level increases according to the autocorrelation of demand change from negative to positive, which means the service level is increasing.

When ADI belongs to [1.32, 3] and the autocorrelation index of demand belongs to $[0.8,1]$, there will be abnormal value. Resulting from the high $\mathrm{CV}^{2}$ of the demand of electricity materials, the service level is relatively low. The abnormal value is as shown in Table 20.

Table 20. Abnormal Value

\begin{tabular}{cc}
\hline Material code & 500065699 \\
\hline Subclass & Cable branch box \\
CV2 & 2.406285 \\
ADI & 1.545455 \\
Demand MAPE & 1.412821 \\
Demand interval MAPE & 0 \\
RGMAE & 0.808193 \\
Correlation of demand & 0.81412 \\
Correlation of demand interval & 0.540257 \\
Cross-correlation & 0.011913 \\
Service level & 0.785368 \\
Cost LOG & 2.611610207 \\
\hline
\end{tabular}

Table 21. Average Service Level (Autocorrelation of Demand Interval)

\begin{tabular}{c|c|c|c|c|c|c|c|c}
\hline & \multicolumn{7}{|c|}{ The range of autocorrelation of demand interval } & \\
\hline ADI & {$[-1,-0.3]$} & {$[-0.3,-0.1]$} & {$[-0.1,0.1]$} & {$[0.1,0.3]$} & {$[0.3,0.5]$} & {$[0.5,0.7]$} & {$[0.7,1]$} & Total \\
\hline $1-1.5$ & 0.98 & 0.98 & 0.98 & 0.97 & 0.97 & 0.95 & 0.92 & 0.97 \\
$1.5-3$ & 0.00 & 0.90 & 0.92 & 0.90 & 0.92 & 0.93 & 0.91 & 0.92 \\
$3-11$ & 0.00 & 0.00 & 0.80 & 0.79 & 0.79 & 0.81 & 0.90 & 0.80 \\
Total & 0.98 & 0.97 & 0.95 & 0.87 & 0.90 & 0.92 & 0.92 & 0.91 \\
\hline
\end{tabular}

Figure 9. Average Service Level (Autocorrelation of Demand Interval)

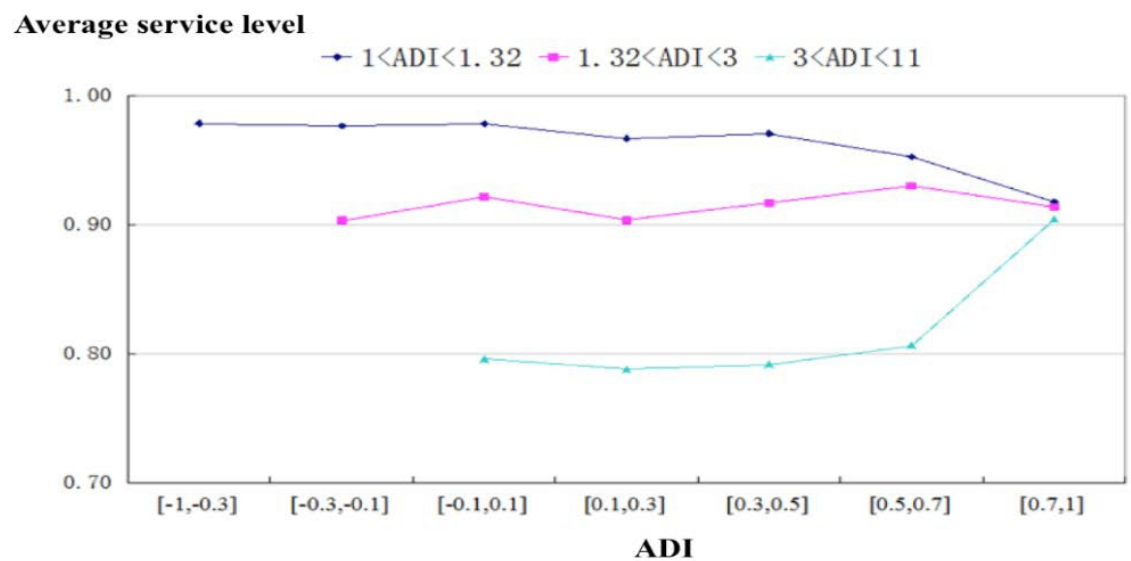


When ADI belongs to [1, 1.32], which means the demand array is partial continuous, the average service level increased with the change of autocorrelation from negative to positive; when ADI is in $[3,11]$, the percentage of value with high forecast accuracy will also raise, which means the service effectiveness is becoming better, meanwhile, under the same autocorrelation of demand interval, the predictive effect of this interval is the worst.

Table 22. Average Service Level (Cross-correlation of Demand and Demand Interval)

\begin{tabular}{|c|c|c|c|c|c|c|}
\hline & \multicolumn{5}{|c|}{ The range of cross-correlation of demand and demand interval } & \multirow[b]{2}{*}{ Total } \\
\hline ADI & {$[-1,-0.2]$} & {$[-0.2,-0.1]$} & {$[-0.1,0]$} & {$[0,0.1]$} & {$[0.1,1]$} & \\
\hline $1-1.5$ & 0.99 & 0.98 & 0.96 & 0.97 & 0.97 & 0.97 \\
\hline $1.5-3$ & 0.00 & 0.96 & 0.90 & 0.94 & 0.00 & 0.92 \\
\hline 3-11 & 0.00 & 0.00 & 0.79 & 0.81 & 0.00 & 0.80 \\
\hline Total & 0.99 & 0.96 & 0.88 & 0.94 & 0.97 & 0.91 \\
\hline
\end{tabular}

Figure 10. Average Service Level (Cross-correlation of Demand and Demand Interval)

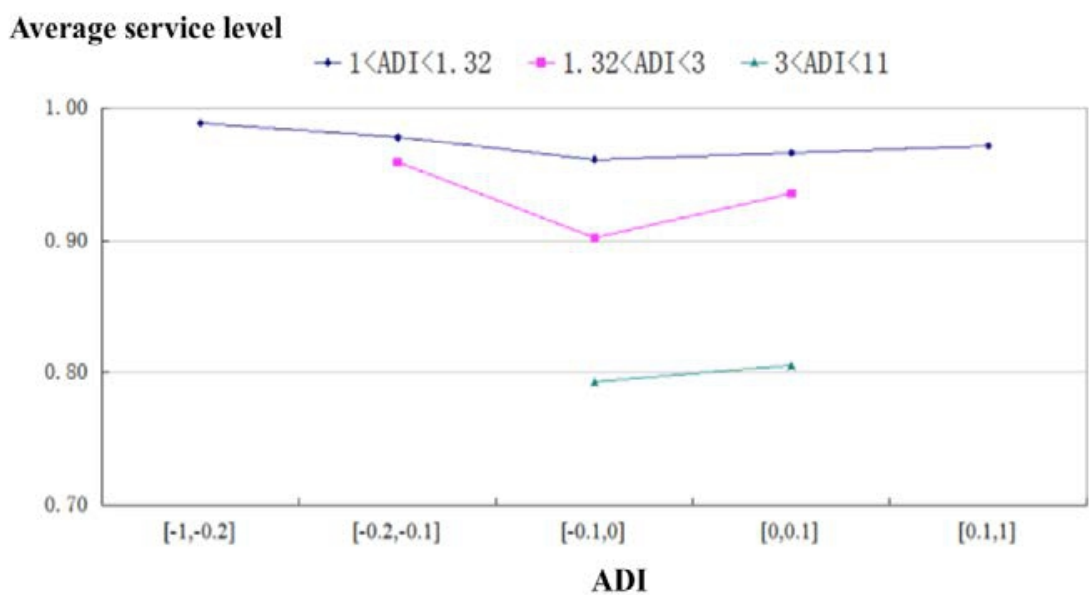

The average service level increased when the change of crosscorrelation of demand and demand interval from weak to strong. In addition, under the same ADI, when the cross-correlation of demand and demand interval is in $[-0.1,0]$, the service level is the lowest.

\section{Conclusion}

It can be concluded from the previous research that the autocorrelation of demand, the autocorrelation of demand interval and the cross-correlation of demand and demand interval have significant effects on the predictive accuracy and the inventory control. When the autocorrelation of the demand is in $[0.4,0.6]$, the predictive effect is the best; when the autocorrelation of the demand is in $[0,0.2]$, the predictive effect is the worst. When the autocorrelation of the demand interval is in $[-1,-0.3]$, the 
predictive accuracy of demand interval is the best; when the autocorrelation of the demand interval is in [0.1, 0.3], the predictive accuracy of demand interval is the worst. When the cross-correlation of demand and demand interval is in $[0,0.1]$, the forecast effect of SBA is the best; when the crosscorrelation of demand and demand interval is in [-0.1, 0], the forecast effect of SBA is the worst. In the terms of average level, the effect of correlation has certain regular pattern. Meanwhile, under the dynamic inventory strategy, the overall average service level of electricity spare parts is good, concentrated between 0.8 and 1 . In the terms of average cost, the effect of correlation has certain regular patterns. Most of the lgAvgCOST of the materials are in [0.5, 1.5], only a small amount of lgAvgCOST is below 0.5 while some lgAvgCOST is over 1.5. Among those materials, the smallest $\operatorname{lgAvgCOST}$ is 0.42 while the largest lgAvgCOST is 3.7, the difference of the two extreme values is large. Therefore, when staffs are predicting or controlling inventory, the effect of correlation of spare parts on forecast and inventory control should be considered to increase the predictive accuracy and the effect of inventory control.

However, this article only have a database that contains 1040 effective values of 36 months, some of the regular patterns are not shown obviously. In future research, larger amount of database is recommended to be used and obtain other efficient regular patterns and characters to provide uses of reference to increase predictive accuracy and service level while decrease stock cost.

\section{Acknowledgments}

The research described in this paper has been funded by the National Natural Science Foundation of China (Grant No. 71302053).

\section{References:}

Alrefaei, M. H., Andrad, ttir, S., \& Graves, S. C. (1999). A Single-Item Inventory Model for a Nonstationary Demand Process. Manufacturing \& Service Operations Management, 1(1), 50-61.

Altay, N., Litteral, L. A., \& Rudisill, F. (2012). Effects of correlation on intermittent demand forecasting and stock control.

Babai, M. Z., Jemai, Z., \& Dallery, Y. (2011). Analysis of order-up-to-level inventory systems with compound Poisson demand. European Journal of Operational Research, 210(210), 552-558.

Eaves, A. H. C. (2002). Forecasting for the ordering and stock-holding of consumable spare parts. Journal of the Operational Research Society, 55(4), 431-437.

Ehrhardt, R. (1979). The Power Approximation for Computing (s, S) Inventory Policies. Management Science, 25(8), 777-786. 
Erkip, N., Hausman, W. H., \& Nahmias, S. (1990). Optimal Centralized Ordering Policies in Multi-Echelon Inventory Systems with Correlated Demands. Management Science, 36(3), 381-392.

Fotopoulos, S., Wang, M. C., \& Rao, S. S. (1988). Safety stock determination with correlated demands and arbitrary lead times. European Journal of Operational Research, 35(2), 172-181.

Johnson, G. D., \& Thompson, H. E. (1975). Optimality of myopic inventory policies for certain dependent demand processes. Management Science, 21(11), 1303-1307.

Levén, E., \& Segerstedt, A. (2004). Inventory control with a modified Croston procedure and Erlang distribution. International Journal of Production Economics, 90(3), 361-367.

Magson, D. W. (1979). Stock Control When the Lead Time Cannot be Considered Constant. Journal of the Operational Research Society, 30(4), 317-322.

Miller, B. L. (1986). Scarf's State Reduction Method, Flexibility, and a Dependent Demand Inventory Model. Operations Research, 34(1), 83-90.

Naddor, E. (1975). Optimal and Heuristic Decisions in Single-and MultiItem Inventory Systems. Management Science, 21(11), 1234-1249.

Porras, E., \& Dekker, R. (2008). An inventory control system for spare parts at a refinery: An empirical comparison of different re-order point methods. European Journal of Operational Research, 184(1), 101-132.

Porteus, E. L. (1985). Numerical Comparisons of Inventory Policies for Periodic Review Systems. Operations Research, 33(33), 134-152.

Ray, W. D. (1980). The Significance of Correlated Demands and Variable Lead Times for Stock Control Policies. Journal of the Operational Research Society, 31(2), 187-190.

Sani, B., \& Kingsman, B. G. (1997). Selecting the best periodic inventory control and demand forecasting methods for low demand items. Journal of the Operational Research Society, 48(48), 700-713.

Shale, E. A., \& Johnston, F. R. (2006). Forecasting for Intermittent Demand: The Estimation of an Unbiased Average. Journal of the Operational Research Society, 57(5), 588-592.

Silver, E. A., Pyke, D. F., \& Peterson, R. (1998). Inventory Management and Production Planning and Scheduling. Interfaces, 31(6), 125-127.

Syntetos, A. A., \& Boylan, J. E. (2005). The accuracy of intermittent demand estimates. International Journal of Forecasting, 21(2), 303-314.

Syntetos, A. A., \& Croston, J. D. (2005). On the categorization of demand patterns. Journal of the Operational Research Society, 56(5), 495-503.

Teunter, R., \& Sani, B. (2009a). Calculating order-up-to levels for products with intermittent demand. International Journal of Production Economics, 118(1), 82-86. 
Teunter, R., \& Sani, B. (2009b). On the bias of Croston's forecasting method. European Journal of Operational Research, 194(194), 177-183.

Wagner, H. M. (1975). Principles of management science : with applications to executive decisions: Prentice-Hall.

Wang, M. C. (1987). Estimating the lead-time demand distribution when the daily demand is non-normal and autocorrelated Hon-Shiang LAU is. European Journal of Operational Research, 29(1), 60-69.

Willemain, T. R., Smart, C. N., Shockor, J. H., \& Desautels, P. A. (1994). Forecasting intermittent demand in manufacturing: a comparative evaluation of Croston's method. International Journal of Forecasting, 10(4), 529-538. 